\title{
She's Got the Look: Inferences from Female Chief Executive Officers' Faces Predict their Success
}

\author{
Nicholas O. Rule • Nalini Ambady
}

Published online: 11 June 2009

(C) Springer Science + Business Media, LLC 2009

\begin{abstract}
Inferences from faces can predict success. This may be particularly important for women, who are often evaluated by their appearance. Here 170 northeastern U.S. undergraduates judged personality traits or leadership ability from the faces of all 20 U.S. Fortune 1,000: 2006 female chief executive officers (CEOs) and we compared these ratings to the same trait ratings made for male CEOs in a previous study. After controlling for cues important for female leaders (attractiveness, affect, age, and masculinity/ femininity), ratings of competence and leadership predicted the amount of profits that the CEOs' companies made and ratings of dominance predicted the amount of individual compensation that the CEOs received. CEOs' success is therefore related to their facial appearance regardless of target and perceiver gender.
\end{abstract}

Keywords Gender Personality · Business .

Person perception $\cdot$ Nonverbal behavior

\section{Introduction}

Women have faced substantial challenges in their advancement toward leadership positions (Oakley 2000). These barriers are thought to be exacerbated in domains that are particularly male-dominated, such as business and management. Although research suggests that the number of women in top executive positions is on the rise (Duehr and Bono 2006), there is still much debate about how the perception of female leaders limits their opportunities to

N. O. Rule $(\bowtie) \cdot$ N. Ambady

Department of Psychology, Tufts University,

490 Boston Avenue,

Medford, MA 02155, USA

e-mail: nicholas.rule@tufts.edu move up the corporate ladder (Eagly and Johnson 1990). A specific point of controversy surrounds the topic of whether male and female executives and chief executive officers are perceived differently, behave differently, and produce different outcomes. We examined how perceptions relate to female Chief Executive Officers' (CEOs') success in the United States and whether these differ from U.S. male CEOs in two studies. In the first study, we compared perceptions of traits from female CEOs' faces to the perceptions of traits from male CEOs' faces reported in a previous study (Rule and Ambady 2008). In the second study, we related the trait perceptions of the female CEOs' faces to measures of their financial success and again compared these to the effects previously observed for male CEOs. Although the current investigation and the majority of studies reviewed are therefore limited to the U.S., the multinational profile of the companies investigated and the increasingly intertwined nature of global economics may therefore make these data relevant for nations outside of the U.S.

Some researchers report considerable differences between male and female business leaders in both behavior and personality. For instance, female managers have been characterized as attending more to the interests of the organization and as considering multiple others' perspectives with regard to planning, thus focusing on warmth or "communal" qualities, whereas male managers have been characterized as attending more to self-interests and planning alone, thus focusing on power or "agentic" qualities (e.g., Lauterbach and Weiner 1996). But the majority of work reporting differences between male and female business leaders relates more to perceptions than to observable differences (see Eagly and Johnson 1990; Eagly and Karau 2002). Indeed, much of the influence on men and women's perceived leadership seems to stem from their 
actual physical appearance. Women and men who exhibit a masculine appearance were found to be perceived as more competent leaders by Sczesny, Spreemann, and Stahlberg (2006) who studied a German sample (see also Sczesny and Kühnen 2004). Similarly, more maturefaced men and women were judged as both more powerful and more likely to be the financial providers in their families in the U.S. (Friedman and Zebrowitz 1992). And despite a vast literature that documents the nearly ubiquitous, positive effects of facial attractiveness (Langlois et al. 2000), an inverse relationship between attractiveness and success has been found for female leaders in business (Heilman and Stopeck 1985). Thus, feminine-appearing women are typically found to be more attractive but are also often seen as worse leaders, whereas masculine-appearing women are typically found to be less attractive but are often seen as better leaders (see also Eagly and Karau 2002).

Previous work has suggested that gender differences in leadership and personality may simply be due to perceived differences, rather than actual differences. Eagly and Karau (2002) reported that individuals' beliefs that men and women ought to differ influenced their perceptions of men's and women's behaviors. Similarly, Hoffman and Hurst (1990) found that gender stereotypes are highly influenced by individuals' behaviors (such as the division of labor), which lead to attributions of differences in personality that would more appropriately be ascribed to the individuals' social roles. Extending this expectationbased perceiver bias, a meta-analysis of studies examining gender and leadership by Eagly and Johnson (1990) found that laboratory studies and studies of hypothetical leaders tended to report gender differences, whereas actual organizational studies did not. They argued that the process of leader selection and socialization into leadership roles effectively removes any actual differences in male and female leaders' behaviors. Thus, the experimental evidence suggesting that men and women lead differently may be a result of the elicitation of gender differences in the lab.

To date, there has been scant evidence of a direct relationship between CEO personality or behavior with company performance (Agle et al. 2006). One limitation of the previous work, however, is that it has principally implemented survey and self-report data from wellinformed respondents (e.g., the CEOs themselves or members of the CEOs' top management teams). But recent work has shown that uninformed judges may provide a better assessment of the link between CEO personality and company performance. Rule and Ambady (2008) found that naïve ratings of personality traits and leadership from the faces of male CEOs from the Fortune 1,000: 2006 predicted the amounts of profits those CEOs' companies made. Specifically, ratings of competence, dominance, and facial maturity (which formed a composite referred to as "power," based on a principal components analysis) of male CEOs was positively related to company profits. In addition, ratings of leadership ability also positively related to company profits.

Noting the importance of physical appearance on the perception and treatment of female business leaders (e.g., Heilman and Stopeck 1985), the primary purpose of the current work was to test whether perceptions of female CEOs' personalities were related to their companies' performance, as has been shown for male CEOs. The current study examined perceptions of the faces of female CEOs from the Fortune 1,000: 2006. Research on the characteristics of female business leaders suggests the importance of the following traits: competence (Nieva and Gutek 1980), dominance (Diekman 2007), facial maturity (Zebrowitz and Montepare 2005), likeability (Heilman and Okimoto 2007), and trustworthiness (Eagly and Karau 2002). These were the traits examined in male CEOs by Rule and Ambady (2008) and, thus, the current study followed the previous methodology by asking a group of uninformed college students to make judgments of these traits from the faces of the female CEOs. Similarly, we also asked a second group of students to make judgments of the potential leadership success of each CEO from her photograph. All of these data were then aggregated across raters and analyzed with CEO as the unit of analysis.

In "Study 1", we then compared these ratings of the female CEOs with those for the male CEOs in Rule and Ambady (2008). Given that males and females are stereotypically associated with different traits, as reviewed above, we wondered whether participants might rate the male and female CEOs' faces differently. For instance, one hypothesis might suggest that women should be perceived higher on communal traits (i.e., likeability and trustworthiness) whereas men should be perceived higher on agentic traits (i.e., competence, dominance, and facial maturity; Lauterbach and Weiner 1996). However, given that the actual prevalence of such differences between men and women is debated (see Eagly and Johnson 1990), a competing hypothesis may be that the men and women would not be perceived differently. This equivalence may be particularly heightened among CEOs, for whom stereotypically masculine traits among both genders may be necessary to achieve success (see Eagly and Karau 2002).

We were also interested in exploring whether participants' genders may have an effect on their ratings of male and female CEOs. Women often outperform men in judgments of nonverbal behaviors (e.g., Hall 1984). However, in some domains of social judgments from faces, men and women appear to perform equally well. For instance, men and women typically show no significant differences in the accuracy of judgments of sexual orientation from faces (e.g., Rule et al. 2008) and Pauker 
et al. (2009) found no differences in men's and women's judgments of racially ambiguous faces. Additionally, Zebrowitz, Montepare, and Lee (1993) found high agreement between male and female raters of White American, Black American, and Korean faces along a host of personality and physical appearance traits for raters from both cultures. Similarly, Cunningham, Roberts, Barbee, Druen, and Wu (1995) found agreement between men and women in their judgments of facial attractiveness among participants in both the U.S. and Taiwan. Based on this literature, we did not expect that men and women would significantly differ in their judgments of CEOs' faces in the current study. To test this formally, however, we included participant gender as a factor in our analyses.

The question of central interest to the current investigation was whether CEOs' genders would affect the relationship between others' perceptions of them and their success; this was the focus of "Study 2". To measure the CEOs' relative success, means for the traits reported in "Study 1" were correlated with the CEOs' company revenues, company profits, and individual compensation as objective indices of success. As in Rule and Ambady's (2008) study of male CEOs, separate groups of coders rated the women's faces for age (Montepare and Zebrowitz 1998), attractiveness (Heilman and Stopeck 1985), and affective expression (Montepare and Dobish 2003), which were used as covariates in the analyses because of their previously documented influence on social judgments of faces. In addition, the present study also included ratings of facial masculinity/femininity as a control because this variable has been found to affect perceptions of female leaders (Sczesny et al. 2006). Based on the research reviewed above, we expected that female CEOs would show similar relationships between trait ratings and success, as did the male CEOs in Rule and Ambady's (2008) previous work. To assess this directly, in "Study 2" we measured whether perceptions of female CEOs' faces would be related to their success and compared these relationships with those for male CEOs in Rule and Ambady (2008).

\section{Study 1}

Are male and female CEOs perceived differently? If so, what role might the perceiver's gender play in inferring traits about men and women? The current study sought to investigate these questions by asking male and female participants to provide ratings of the faces of female Fortune 1,000 CEOs along various traits. Critically, we also included data from Rule and Ambady's (2008) previous study of trait perceptions from male CEOs' faces to compare individuals' perceptions of male versus female CEOs. Specifically, we wondered whether male and female
CEOs might be perceived differently in association with male- and female-stereotyped traits. Thus, we expected that female CEOs might be rated significantly higher on communal traits, such as likeability and trustworthiness, and that male CEOs might be rated significantly higher on agentic traits, such as competence, dominance, and facial maturity (see also Lauterbach and Weiner 1996).

\section{Method}

\section{Participants}

Undergraduate volunteers $(N=170)$ participated for partial credit in an introductory psychology course at a northeastern U.S. university. Participants were divided into two conditions: 90 participants (ages 18-22; 45 females, 45 males) were presented with the faces of female CEOs and asked to rate the faces on a series of personality traits and the remaining 80 participants (ages 18-22; 40 females, 40 males) were asked to rate each female CEO's face for how successful she would be at leading a company. Participants were not aware that they were rating CEOs and no participants recognized any of the targets nor reported any awareness that the task was examining CEOs; hence, participants were naive perceivers.

In addition, data for ratings of male CEOs were included from Rule and Ambady (2008)'s previously published work. In that study, 100 participants were divided into the same two conditions as above. Fifty participants (ages 1822; 32 females, 18 males) were presented with the faces of male CEOs and asked to rate the faces on a series of personality traits; two participants (one male, one female) recognized CEOs and were eliminated from analysis (final $n=48$ ). The remaining 50 participants (ages 18-22; 33 females, 17 males) were asked to rate each male CEO's face for how successful he would be at leading a company; one male participant recognized a CEO and was eliminated from analysis (final $n=49$ ).

\section{Stimuli}

Photos of male and female CEOs from the U.S. Fortune 1,000: 2006 were downloaded from their companies' websites or annual reports. As reported in Rule and Ambady (2008), we selected the CEOs from the top 25 ranks (ranks 1-25) and bottom 25 ranks (ranks 976-1,000) of the Fortune 1,000: 2006, all but one of whom was male. Pre-testing showed that one male CEO was a statistical outlier and was therefore excluded and two additional male CEOs led companies that were acquired during the fiscal year from which the CEOs were chosen. We therefore had a final sample of 46 male CEOs, all of whom were ostensibly Caucasian. 
For the current study, we selected all of the female CEOs from the Fortune 1,000: 2006. In total, there were only 20 women in the Fortune 1,000 listing for fiscal year 2005, spanning a variety of ranks (range: 111 to $992 ; M d n=505$ ). All but one of the CEOs was ostensibly Caucasian (the target's race did not appear to skew participants' perceptions of her, as all ratings were within a single standard deviation of the mean for each trait). Both the male and female stimuli were prepared following the same procedures: Each image was cropped tightly around the CEO's head to remove all extra-facial information, was converted to gray scale, and was standardized in size.

\section{Procedure}

Procedures were the same as those reported in Rule and Ambady (2008). Participants in the trait rating condition were instructed that they would be seeing a series of women's faces appear on a computer screen and that they were to make judgments of the faces along various dimensions. Participants rated 5 traits, each consisting of a single item rated along a 7-point Likert-type scale anchored at 1 ("Not at all X") and 7 ("Very X"): competence (interrater reliability: Cronbach's $\alpha=.96$ ), dominance (inter-rater reliability: Cronbach's $\alpha=.95$ ), likeability (inter-rater reliability: Cronbach's $\alpha=.94$ ), facial maturity (inter-rater reliability: Cronbach's $\alpha=.88$ ), and trustworthiness (interrater reliability: Cronbach's $\alpha=.93$ ). Each face was presented in random order for each trait using DirectRT software. Stimuli were blocked by traits and the order of the blocks was also random. Thus, participants would receive instructions at the beginning of each block, asking them to rate the following faces for the next given trait and the scale was presented below each face as it was presented on the computer screen. Although the presentation of each face was not limited in time, participants were instructed to make their judgments as quickly and accurately as possible.
Participants in the leadership rating condition were instructed that they would be seeing a series of women's faces appear on a computer screen and that they were to judge each face as to how successful they believed the person would be at leading a company along a 7-point scale: $1=$ Not at all successful and $7=$ Very successful (inter-rater reliability: Cronbach's $\alpha=.95$ ). Again, no participants recognized any of the targets nor reported any suspicion or familiarity with the nature of the task. Hence, participants were naive perceivers.

\section{Results}

Male and female participants' ratings were separately averaged together for each target on each trait, thereby yielding two mean ratings for each CEO on each of the six dimensions: males' average rating of the CEO on each variable and females' average rating of the $\mathrm{CEO}$ on each variable (see Table 1 for descriptive statistics). Thus, each CEO had 12 scores comprising male and female participants' ratings along the six variables (leadership, competence, dominance, facial maturity, likeability, and trustworthiness). These mean scores were then submitted to a 2 (participant gender: male or female) X 2 (CEO gender: male or female) doubly multivariate analysis of variance (MANOVA) in which targets (CEOs) were treated as the unit of analysis. Due to the unequal cell sizes (20 female CEOs versus 46 male CEOs), Type I sums of squares were used to estimate effects, though the results did not substantially differ when the analysis was modeled using Type III sums of squares. In addition, a violation of homogeneity of variance was observed using Box's $M$ test [Box's $M=194.57, F(78$, $4610.68)=1.84, p<.001]$. Effects are therefore reported using Pillai's trace.

Results of the MANOVA showed a significant multivariate main effect of CEO gender: Pillai's trace $=.35 ; F(6$, 59) $=5.21, p<.001, \eta_{\text {partial }}{ }^{2}=.35$. We therefore decom-
Table 1 Means and standard errors for trait ratings of male and female CEOs as rated by male and female participants in "Study 1".

Scales for all traits range between 1 and 7; Data for male CEOs are from Rule and Ambady (2008)

${ }^{a}$ Means significantly differ at $p<.001$

${ }^{\mathrm{b}}$ Means significantly differ at $p=.008$

${ }^{\mathrm{c}}$ Means significantly differ at $p=.003$

\begin{tabular}{|c|c|c|c|c|c|c|c|c|}
\hline \multirow[t]{3}{*}{ Trait } & \multicolumn{4}{|c|}{ Female participants } & \multicolumn{4}{|c|}{ Male participants } \\
\hline & \multicolumn{2}{|c|}{ Female CEOs } & \multicolumn{2}{|c|}{ Male CEOs } & \multicolumn{2}{|c|}{ Female CEOs } & \multicolumn{2}{|c|}{ Male CEOs } \\
\hline & $M$ & $S E$ & $M$ & $S E$ & $M$ & $S E$ & $M$ & $S E$ \\
\hline Leadership & 4.22 & .14 & 4.40 & .08 & 3.84 & .15 & 4.31 & .06 \\
\hline \multicolumn{9}{|l|}{ Agentic Traits } \\
\hline Competence & 4.51 & .12 & 4.79 & .08 & 4.47 & .12 & 4.80 & .08 \\
\hline Dominance & 4.25 & .14 & 4.53 & .09 & $4.07^{\mathrm{a}}$ & .13 & $4.62^{\mathrm{a}}$ & .08 \\
\hline Facial Maturity & $4.87^{\mathrm{c}}$ & .11 & 4.99 & .08 & $4.60^{\mathrm{b}, \mathrm{c}}$ & .13 & $5.04^{\mathrm{b}}$ & .09 \\
\hline \multicolumn{9}{|l|}{ Communal Traits } \\
\hline Likeability & 4.19 & .13 & 4.10 & .09 & 4.26 & .13 & 4.08 & .09 \\
\hline Trustworthiness & 4.16 & .12 & 3.86 & .08 & 4.14 & .12 & 3.92 & .08 \\
\hline
\end{tabular}


posed this by examining the individual univariate effects for the six dependent measures using a Bonferronicorrected significance threshold $(\alpha=.0083)$. Results of the univariate tests, however, showed no significant differences between male and female CEOs for any of the six traits: all $F$ 's $<7.31$, all $p$ 's $>.009$, all $\eta_{\text {partial }}{ }^{2}$ 's $<.10$.

Although we did not observe a significant multivariate main effect for participant gender [Pillai's trace $=.16 ; F(6$, $\left.59)=1.86, p=.10, \eta_{\text {partial }}{ }^{2}=.16\right]$, we did observe a significant participant gender X CEO gender multivariate interaction: Pillai's trace $=.32 ; F(6,59)=4.52, p=.001$, $\eta_{\text {partial }}{ }^{2}=.32$. Decomposition of this interaction at the univariate level (Bonferroni-corrected $\alpha=.0083$ ) showed significant interactions between participant and CEO gender for ratings of dominance $[F(1,64)=9.85, p=$ $\left..003, \eta_{\text {partial }}{ }^{2}=.13\right]$ and facial maturity $[F(1,64)=14.51$, $\left.p<.001, \eta_{\text {partial }}{ }^{2}=.19\right]$. We therefore examined the simple effects of each of these interactions via $t$-tests with a Bonferroni-corrected significance threshold $(\alpha=.0125)$. Examination of the means (see Table 1) suggested that the interaction of participant and CEO gender for ratings of dominance was primarily driven by male participants' significantly higher ratings of male CEOs over female CEOs: $t(64)=3.61, p<.001, r=.41$. Similarly, the interaction effect among ratings of facial maturity appeared to be supported by male participants' significantly higher ratings of male CEOs over female CEOs $[t(64)=2.76, p=.008$, $r=.33$ ], as well as their significantly lower ratings of female CEOs as compared to female participants' ratings of the female CEOs: $t(19)=3.34, p=.003, r=.61$.

\section{Discussion}

Contrary to our expectations, male and female CEOs were not perceived differently in accord with gender stereotypes about agency and communality. Although there was an overall multivariate effect suggesting a difference between the mean ratings of male and female CEOs, this effect was not supported by differences along any particular trait. Similarly, male and female participants' ratings of traits did not differ. However, when both participant gender and CEO gender were crossed, male and female participants appeared to rate male and female CEOs differently on two agentic, power-related traits: dominance and facial maturity. Specifically, male participants rated male CEOs as significantly more dominant and facially mature than female CEOs. In addition, male participants' judgments of female CEOs' facial maturity were significantly lower (i.e., more babyfaced) than female participants' judgments of female CEOs' facial maturity.

It is not surprising that male and female targets were perceived differently in terms of dominance and facial maturity. Indeed, stereotypes and actual physiological differences indicate that males and females systematically differ in their physical expression of these traits (e.g., Friedman and Zebrowitz 1992; Mazur 2005; Zebrowitz 1997). Furthermore, dominance and facial maturity are often highly correlated (Zebrowitz 1997) and may therefore tap a common underlying trait (Rule and Ambady 2008; see also Zebrowitz and Montepare 2005).

Although it is not clear why men but not women should perceive these traits differently, gender differences in social perception may partially explain these effects. Some evidence suggests that men may be more attentive to status-bearing cues (e.g., Mazur 2005) and may be more likely to apply gender stereotypes (e.g., Smiler and Gelman 2008). One explanation for the present effects may therefore be that men are either more attuned to cues of dominance or that they were simply applying gender stereotypes more than women were when rating the faces.

Critically, however, no participant rated both male and female CEOs, preventing the occurrence of contrast effects or shifting standards (see Biernat and Manis 1994). Therefore, further exploration of these differences might be worthwhile, especially in the domain of business where stereotypes about gender may be particularly consequential (Eagly and Karau 2002; Oakley 2000).

\section{Study 2}

"Study 1" showed that male and female CEOs were perceived differently but this difference was not reflected on any particular trait. How is this overall difference in perception related to performance outcomes? Rule and Ambady (2008) showed that naive perceivers' judgments of the faces of male CEOs were significantly correlated with the CEOs' success. "Study 2" therefore sought to examine whether this is true also for female CEOs and whether these effects might differ according to the perceiver's gender. Based on the results of "Study 1" and the previous literature, we expected that inferences of traits from the faces of female CEOs should predict their success as it does for male CEOs.

\section{Method}

Participants' ratings of the leadership ability, competence, dominance, likeability, and trustworthiness of female CEOs in "Study 1" were used in the current study, as well. Specifically, we were interested in testing the relationship between these perceived traits with outcome variables indexing the CEOs' relative success. We therefore acquired information about the female CEOs' individual and companies' financial performance. Information about company financial performance (i.e., annual revenues and 
profits) was obtained from the 2006 listing on the Fortune Web site (http://money.cnn.com/magazines/fortune/fortune 500 ) or the companies' annual reports. We also obtained information about the CEOs' cash and total (i.e., including stock benefits) annual compensation from Google Finance (http://finance.google.com) for fiscal year 2005 (information about individual compensation could not be obtained for two of the CEOs and so we correlated the individual performance measures independently of the company performance data).

In addition, considering the influence of attractiveness and affective expression on judgments of appearanceparticularly for women in leadership - we sought to control for the effects of affect and attractiveness. Two naïve independent raters coded the faces for affective expression along a 7-point scale $(1=$ Neutral, $4=$ Happy, $7=$ Very happy; inter-rater reliability: Cronbach's $\alpha=.83$ ). A separate group of 10 naïve independent raters ( $n=5$ males) coded the faces for facial attractiveness along a 7-point scale $(1=$ Not at all attractive, $7=$ Very attractive ; interrater reliability: Cronbach's $\alpha=.83$ ). Three naïve independent raters also coded the faces for masculinity/femininity (Sczesny et al. 2006) along a 7-point scale $(1=$ Feminine, 7 = Masculine; inter-rater reliability: Cronbach's $\alpha=.74)$. Finally, CEOs' ages were obtained from Google Finance (http://finance.google.com). The targets' ages and mean scores for attractiveness, affect, and masculinity/femininity were used as statistical covariates in the analyses.

Finally, we compared these correlations between trait perceptions and performance measures for male versus female participants. In addition, we also compared the relationships between trait perceptions and performance measures for female CEOs in the current study with the relationships reported for male CEOs in Rule and Ambady's (2008) previously published work.

\section{Results and Discussion}

As male and female participants showed no significant differences in "Study 1", we initially collapsed across participant gender in our analyses. Trait and leadership ratings were therefore averaged across participants irrespective of participant gender for each CEO: competence $(M=4.49, S E=.14)$, dominance $(M=4.16, S E=.14)$, facial maturity $(M=4.74, S E=.09)$, likeability $(M=4.22, S E=.13)$, trustworthiness $(M=4.15, S E=.11)$, and leadership $(M=$ 4.02, $S E=.14$ ). Partial correlations controlling for age (in years; $M=52.60, S D=6.08)$, attractiveness $(M=3.26$, $S E=.20)$, affect $(M=3.78, S E=.25)$, and facial masculinity/ femininity $(M=4.11, S E=.25)$ indicated a significant positive correlation between participants' perceptions of competence with company profits $[r(14)=.52, p=.04$; see Fig. 1] and perceptions of leadership with company profits $[r(14)=.60$,

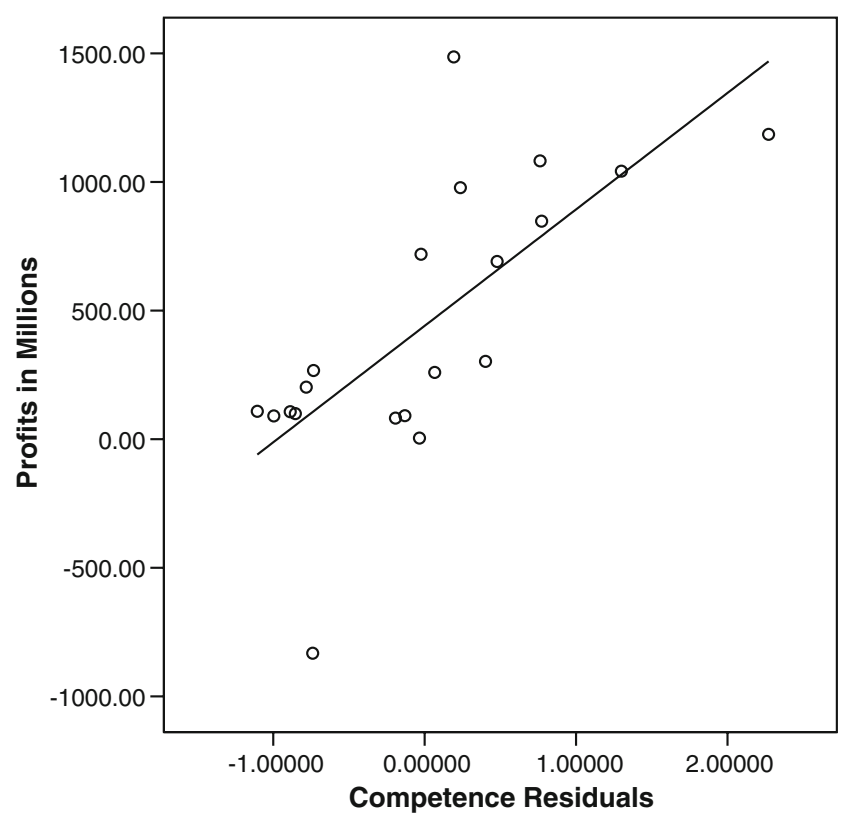

Fig. 1 Scatter plot and trend line showing standardized residuals of the relationship between participants' naive inferences of competence from female CEOs' faces and the CEOs' company profits after controlling for CEO age, affective expression, facial attractiveness, and facial masculinity/femininity.

$p=.01$; see Fig. 2]; correlations for all variables are presented in Table 2. Thus, female CEOs who were perceived as more competent and as more likely to be a successful leader based on their facial appearance led companies that acquired more profit in fiscal year 2005 . Correlations between company profits with all other traits were non-significant (all $r$ 's $<.45$, all $p$ 's $>.08$ ) and none of the traits showed a significant relationship with company revenues (all $r$ 's $<.39$, all $p$ 's $>.14$ ), replicating the previous work examining male CEOs (Rule and Ambady 2008). Notably, we also found positive relationships between ratings of attractiveness and company revenues and profits - contrary to previous work showing that female CEOs' attractiveness was negatively related to their professional success (e.g., Heilman and Stopeck 1985).

We then examined these effects taking into account participants' genders. Ratings by female participants showed the same relationships between profits and competence $[r(14)=.45, p=.04]$ and profits and leadership $[r(14)=.63, p=.004]$ as did the overall, mixedgender group. Ratings by male participants also showed the same relationship between profits and competence $[r(14)=.43, p=.05]$ and between profits and leadership $[r(14)=.47, p=.03]$ as did the mixed-gender group. Finally, meta-analytic comparisons of effect sizes showed no differences between the effects for male and female participants with regard to competence $[Z=.06, p=.47]$ or 


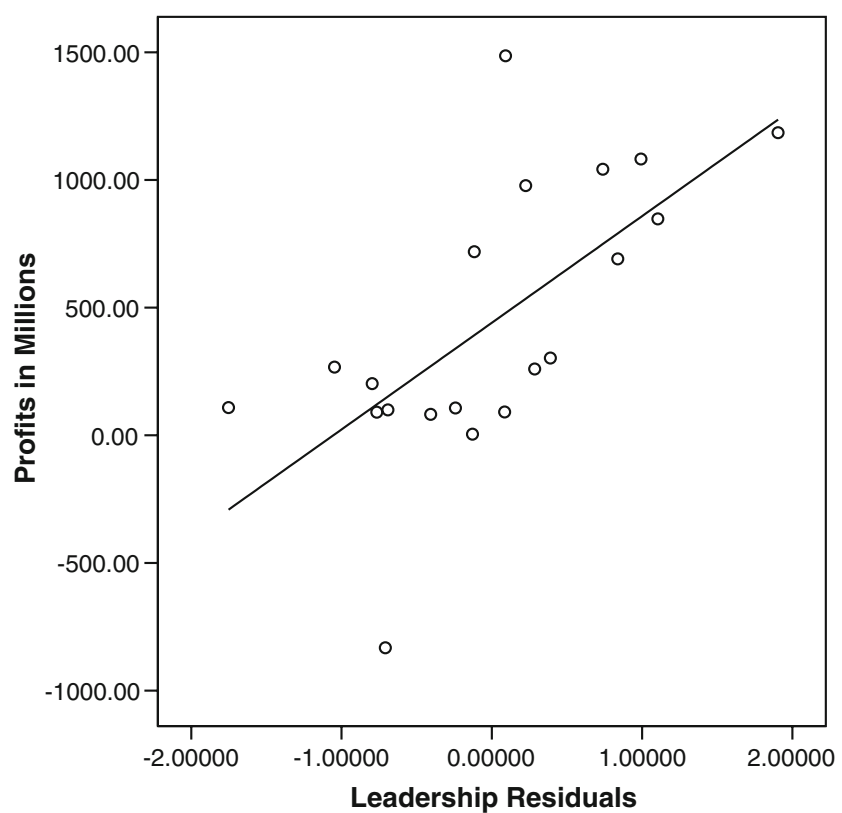

Fig. 2 Scatter plot and trend line showing standardized residuals of the relationship between participants' naive inferences of likely leadership success from female CEOs' faces and the CEOs' company profits after controlling for CEO age, affective expression, facial attractiveness, and facial masculinity/femininity.

leadership $[Z=.60, p=.28]$. Thus, male and female raters showed similar perceptions of the female CEOs; a departure from previous findings that have demonstrated differences in perceiver gender for survey data (e.g., Garcia-Retamero and Lopez-Zafra 2006 investigating a Spanish sample; see also Eagly and Johnson 1990).

As mentioned above, information about individual compensation could not be obtained for two of the CEOs and so we correlated the two measures independently of the company performance data. The previous work examining male CEOs found no relationships between participants' perceptions and CEOs' individual compensation (Rule and Ambady 2008). However, after again controlling for age, affective expression, attractiveness, and masculinity/femininity, perceptions of dominance were significantly related to both cash compensation $[r(12)=.68, p=.008]$ and total compensation $[r(12)=.57, p=.03]$ for female CEOs. Neither cash nor total compensation was significantly related to any of the other personality traits, leadership, company revenues, or company profits (all $r$ 's $<.47$, all $p$ 's $>.09$ ). Thus, the relationship between perceptions of dominance and compensation seems to be unique to perceptions of dominance among female CEOs. Again, both male $\left[r(12)_{\text {Cash compensation }}=.63, p=.008 ; r(12)_{\text {Total compensation }}=\right.$ $.51, p=.03]$ and female $[r(12)$ Cash compensation $=.66, p=.005$; $r(12)$ Total compensation $=.57, p=.02]$ participants showed roughly the same effects as the mixed-gender group and these effects were again statistically equivalent for both male and female participants $(Z$ Cash compensation $=.12, p=.45$; $Z_{\text {Total compensation }}=.20, p=.42$ ).

Finally, we compared the findings from the current study to those of Rule and Ambady (2008). Meta-analytic comparisons of the partial correlations between company profits and each of the traits rated (leadership, competence, dominance, facial maturity, likeability, and trustworthiness) while controlling for the three covariates common to both studies (age, affect, and attractiveness) showed no significant differences between the correlations in the current study examining female CEOs with those in Rule and Ambady's (2008) study examining male CEOs (all Z's $<1$

Table 2 Correlations between uninformed perceptions of traits from women CEOs' faces with companies' financial success, as measured through annual revenues and profits.

\begin{tabular}{|c|c|c|c|c|c|c|c|c|c|c|c|}
\hline Measure & 1 & 2 & 3 & 4 & 5 & 6 & 7 & 8 & 9 & 10 & 11 \\
\hline 1. Company revenues & & .39 & .08 & -.10 & -.08 & .09 & .23 & -.05 & & & \\
\hline 2. Company profits & $.47 *$ & & $.60 * *$ & $.52 *$ & .26 & .33 & .45 & .28 & & & \\
\hline 3. Leadership & .34 & .31 & & $.88 * * *$ & $.64 * *$ & $.67 * *$ & $.63 * *$ & $.65^{* *}$ & & & \\
\hline 4. Competence & .20 & .33 & $.94 * * *$ & & .45 & $.82 * * *$ & $.58 * *$ & $.88 * * *$ & & & \\
\hline 5. Dominance & .24 & .14 & $.85 * * *$ & $.73 * * *$ & & .15 & .61 & .10 & & & \\
\hline 6. Facial maturity & .29 & .42 & $.59 * *$ & $.73 * * *$ & .26 & & .38 & $.92 * * *$ & & & \\
\hline 7. Likeability & .20 & .40 & .39 & .38 & $.46^{*}$ & .15 & & .43 & & & \\
\hline 8. Trustworthiness & .04 & .33 & $.50 * *$ & $.72 * * *$ & .17 & $.84 * * *$ & .37 & & & & \\
\hline 9. Age & .18 & .35 & -.27 & -.31 & -.15 & -.22 & .21 & -.17 & & & \\
\hline 10. Affect & .13 & .34 & .05 & .17 & -.13 & $.66^{* *}$ & -.11 & .39 & -.18 & & \\
\hline 11. Attractiveness & .41 & .06 & $.81 * * *$ & $.71 * * *$ & $.76^{* * *}$ & .40 & .02 & .16 & -.25 & .02 & \\
\hline 12. Masculinity/femininity & -.27 & -.05 & $-.49 *$ & $-.49 *$ & -.29 & $-.57 * *$ & .32 & -.21 & $.52 * *$ & $-.50 * *$ & $-.66^{* *}$ \\
\hline
\end{tabular}

Values above the diagonal are partial correlations, which controlled for the age, affective expression, attractiveness, and masculinity/femininity of the CEOs' faces $(d f=14)$. Values below the diagonal are simple correlations $(d f=18)$

${ }^{*} p<.05, * * p<.025, * * * p<.001$ 
Table 3 Partial correlations between CEOs' company profits and each of the traits rated in "Study 2" (female CEOs) and in Rule and Ambady (2008; male CEOs) when controlling for age, affect, and attractiveness. $Z$-scores represent the meta-analytic differences comparing the correlations for the male and female CEOs between the two studies.

\begin{tabular}{llll}
\hline Trait rated & $r_{\text {Male CEOs }}$ & $r_{\text {Female CEOs }}$ & $|\mathrm{Z}|$ \\
\hline Leadership & .30 & .60 & 1.24 \\
Competence & .23 & .51 & 1.06 \\
Dominance & .37 & .24 & .46 \\
Facial maturity & .28 & .39 & .40 \\
Likeability & -.11 & .33 & 1.46 \\
Trustworthiness & -.17 & .29 & 1.51 \\
\hline
\end{tabular}

None of the comparisons $(Z$ 's) between male $(d f=41)$ and female $(d f=$ 15) CEOs were statistically significant at $\alpha=.05$

$1.51 \mid$, all $p$ 's > .06; see Table 3). We may therefore conclude that perceptions of leadership from the faces of male and female Fortune 1,000 CEOs possess the same predictive value since the relationships between the trait judgments and company profits did not significantly differ across the targets' genders.

\section{General Discussion}

Perceptions of competence and leadership ability from the faces of female CEOs were correlated with the amount of profits that their companies earned. After controlling for variables that have been found important in the personality and person perception literature for facial physiognomy and affect, and in the management literature for perceptions of female leaders, the judgments of naïve, uninformed college students (regardless of their gender) predicted the success of Fortune 1,000 companies from just the faces of their CEOs.

Although previous work has already shown that inferences from the faces of male CEOs from the highest and lowest ranks of the Fortune 1,000 also predicted company profits, the current work extends these findings to the domain of female business leaders. The investigation of similarities and differences between male and female leaders, and particularly business executives, has produced somewhat mixed results. Whereas much research suggests that women and men lead, and are perceived to lead, in distinct ways (e.g., Lauterbach and Weiner 1996), others have explained these differences as often being due to experimental artifacts (e.g., Eagly and Johnson 1990). The current work supports the latter argument: similar relationships between company profits and perceived leadership ability were found for male CEOs in previous work (Rule and Ambady 2008) and for female CEOs in the current work, suggesting that the ability to infer success from faces is applicable to both male and female CEOs. These similar findings for male and female CEOs might add evidence to the suggestion that social roles influence the relationship between perceptions of individuals' traits and their success (see Hoffman and Hurst 1990) such that when males' and females' social roles are the same, perceptions of traits do not greatly differ. Conversely, it remains possible that individuals with particular traits are motivated toward becoming CEOs, regardless of their gender. At present, however, such conclusions are only speculative and further research will need to revisit this issue in additional domains.

One gender difference between CEOs that did emerge was the relationship between dominance and CEOs' individual compensation. For female CEOs, ratings of dominance were related to both cash compensation and total annual earnings. The previous work on male CEOs found no relationship between participants' perceptions and either measure of CEO compensation. This effect could possibly be due to differences in the way that dominance is perceived and negotiated for males versus females (see Ritter and Yoder 2004). Indeed, the results of the MANOVA in "Study 1" showed that male and female CEOs were rated significantly differently on dominance when rated by male participants. Therefore, the role of dominance in both informed (e.g., Diekman 2007) and naive (the current work) judgments of leadership may continue to provide an interesting venue for future research on gender differences and leadership. Similarly, comparisons between informed (expert) and uninformed (naïve) judges for other traits may provide interesting insights to our capacity for perceiving these traits, as well.

Although the current data are intriguing, they are also limited. Because there are so few female CEOs in the Fortune 1,000 , the number of targets in the current work was relatively small. This could not be helped and we used the entire population of targets available. These data do, however, replicate previous work done with male CEOs. Thus, the effect that they demonstrate appears to be reliable and fairly robust. Additionally, the current and previous studies are both limited in that they exclusively examine American participants' judgments of American CEOs. Future work should explore whether these effects extend cross-culturally, paying particular attention to the role that cultural differences among both perceivers (those making the judgments) and targets (the CEOs being judged) may have on the relationship between individuals' appearance and their success. This will help to further our understanding of the degree to which these effects do actually represent a relationship between CEOs' appearance and their success, independent of expertise in perceiving cultural ingroup and cultural outgroup faces. 


\section{Conclusion}

The faces of female CEOs therefore communicated information about their personality and behavior that was predictive of their personal and professional financial success. Previous work that has examined the relationship between female leaders and their success has typically done so in a manner that directly contrasts their performance with that of their male colleagues. The current work, however, examined the perceptions of female Fortune 1,000 CEOs independently of their male counterparts. Here we found that women's facial appearances predicted their companies' success, replicating a pattern previously reported for men. In addition, female CEOs' facial appearances also predicted their personal financial success as executives - a pattern previously not found for male CEOs. It remains a question for future research as to whether these relationships are the product of companies selecting CEOs with a particular appearance or individuals with a particular appearance being advantaged toward becoming CEOs. However, we are able to conclude that the subjective and consensual perceptions of female CEOs predict objective performance and that this information is reliably inferred from judgments of personality from the face.

Acknowledgements This research was supported in part by National Science Foundation grant BCS-0435547 to Nalini Ambady and a National Science Foundation Graduate Research Fellowship to Nicholas O. Rule.

\section{References}

Agle, B. R., Nagarajan, N. J., Sonnenfeld, J. A., \& Srinivasan, D. (2006). Does CEO charisma matter? An empirical analysis of the relationships among organizational performance, environmental uncertainty, and top management team perceptions of CEO charisma. Academy of Management Journal, 49, 161-174.

Biernat, M., \& Manis, M. (1994). Shifting standards and stereotypebased judgments. Journal of Personality and Social Psychology, $66,5-20$.

Cunningham, M. R., Roberts, A. R., Barbee, A. P., Druen, P. B., \& Wu, C. (1995). "Their ideas of beauty are, on the whole, the same as ours": consistency and variability in the cross-cultural perception of female physical attractiveness. Journal of Personality and Social Psychology, 68, 261-279.

Diekman, A. B. (2007). Negotiating the double bind: interpersonal and instrumental evaluations of dominance. Sex Roles, 56, 551561.

Duehr, E. E., \& Bono, J. E. (2006). Men, women, and managers: are stereotypes finally changing? Personnel Psychology, 59, 815-846.

Eagly, A. H., \& Johnson, B. T. (1990). Gender and leadership style: a meta-analysis. Psychological Bulletin, 108, 233-256.

Eagly, A. H., \& Karau, S. J. (2002). Role congruity theory of prejudice toward female leaders. Psychological Bulletin, 109, 573-598.

Friedman, H., \& Zebrowitz, L. A. (1992). The contribution of typical sex differences in facial maturity to sex role stereotypes. Personality and Social Psychology Bulletin, 18, 430-438.
Garcia-Retamero, R., \& Lopez-Zafra, E. (2006). Prejudice against women in male-congenial environments: perceptions of gender role congruity in leadership. Sex Roles, 55, 51-61.

Hall, J. (1984). Nonverbal sex differences: Communication accuracy and expressive style. Baltimore, MD: Johns Hopkins University Press.

Heilman, M. E., \& Okimoto, T. G. (2007). Why are women penalized for success at male tasks?: the implied communality deficit. Journal of Applied Psychology, 92, 81-92.

Heilman, M. E., \& Stopeck, M. H. (1985). Attractiveness and corporate success: different causal attributions for males and females. Journal of Applied Psychology, 70, 379-388.

Hoffman, C., \& Hurst, N. (1990). Gender stereotypes: perception or rationalization? Journal of Personality and Social Psychology, $58,197-208$.

Langlois, J. H., Kalakanis, L., Rubinstein, A. J., Larson, A., Hallam, M., \& Smoot, M. (2000). Maxims or myths of beauty? A meta-analytic and theoretical review. Psychological Bulletin, 126, 390-423.

Lauterbach, K. E., \& Weiner, B. J. (1996). Dynamics of upward influence: how male and female managers get their way. Leadership Quarterly, 7, 87-107.

Mazur, A. (2005). The biosociology of dominance and deference. Lanham, MD: Rowman \& Littlefield.

Montepare, J. M., \& Dobish, H. (2003). The contribution of emotion perceptions and their overgeneralizations to trait impressions. Journal of Nonverbal behavior, 27, 237-254.

Montepare, J. M., \& Zebrowitz, L. A. (1998). Person perception comes of age: the salience and significance of age in social judgment. Advances in Experimental Social Psychology, 30, 93161.

Nieva, V. F., \& Gutek, B. (1980). Sex effects on evaluation. Academy of Management Review, 5, 267-276.

Oakley, J. G. (2000). Gender-based barriers to senior management positions: understanding the scarcity of female CEOs. Journal of Business Ethics, 27, 321-334.

Pauker, K., Weisbuch, M., Ambady, N., Sommers, S. R., Adams, R. B., Jr., \& Ivcevic, Z. (2009). Not so black and white: memory for ambiguous group members. Journal of Personality and Social Psychology, 96, 795-810.

Ritter, B. A., \& Yoder, J. D. (2004). Gender differences in leader emergence persist even for dominant women: an updated confirmation of role congruity theory. Psychology of Women Quarterly, 28, 187-193.

Rule, N. O., \& Ambady, N. (2008). The face of success: inferences from chief executive officers' appearance predict company profits. Psychological Science, 19, 109-111.

Rule, N. O., Ambady, N., Adams, R. B., Jr., \& Macrae, C. N. (2008). Accuracy and awareness in the perception and categorization of male sexual orientation. Journal of Personality and Social Psychology, 95, 1019-1028.

Sczesny, S., \& Kühnen, U. (2004). Meta-cognition about biological sex and gender-stereotypic physical appearance: consequences for the assessment of leadership competence. Personality and Social Psychology Bulletin, 30, 13-21.

Sczesny, S., Spreemann, S., \& Stahlberg, D. (2006). Masculine = competent? Physical appearance and sex as sources of genderstereotypic attributions. Swiss Journal of Psychology, 65, 15-23.

Smiler, A. P., \& Gelman, S. A. (2008). Determinants of gender essentialism in college students. Sex Roles, 58, 864-874.

Zebrowitz, L. A. (1997). Reading faces: Window to the soul? Boulder, CO: Westview.

Zebrowitz, L. A., \& Montepare, J. M. (2005). Appearance does matter. Science, 308, 1565-1566.

Zebrowitz, L. A., Montepare, J. M., \& Lee, H. K. (1993). They don't all look alike: individuated impressions of other racial groups. Journal of Personality and Social Psychology, 65, 85-101. 